\title{
The rumen and potassium homeostasis: a model ${ }^{*}$
}

\author{
F. Stumpff ${ }^{1}$ and H. Martens \\ Department of Veterinary Physiology, Free University of Berlin \\ Oertzenweg 19b, D-14163 Berlin, Germany
}

\begin{abstract}
The ruminant has to be able to regulate potassium metabolism over an extremely wide range of intake. When related to body weight, dietary potassium intake of ruminants frequently exceeds that of humans by a factor of over ten, and experimental situations suggest that the toxic threshold for ingestion of potassium is considerably higher. While a number of studies have addressed the outstanding ability of the ruminant kidney to extrude potassium, the role of the rumen in maintaining potassium homeostasis in sheep and cows by serving as a reservoir for the redistribution of potassium has received considerably less attention. Based on current and past studies at the level of the cell, the tissue and the animal, we present a model for the regulation of ruminal transport that may help in the understanding of the variable responses of the rumen epithelium to dietary potassium intake, and the role of magnesium in mediating these responses.
\end{abstract}

KEY WORDS: rumen, potassium, magnesium, cation channel, patch-clamp, sheep

\section{INTRODUCTION}

The ability of ruminants to produce milk and gain weight while ingesting grass and hay relies on their ability to deal with large amounts of potassium. When related to body weight, the upper limit of daily voluntary human potassium intake is $1.4 \mathrm{mmol} / \mathrm{kg} \cdot \mathrm{d}$ (Giebisch, 1998). Conversely, ruminants have to be able to tolerate variations in $\mathrm{K}^{+}$uptake from $3.8 \mathrm{mmol} / \mathrm{kg} \cdot \mathrm{d}$ to almost $20 \mathrm{mmol} / \mathrm{kg} \cdot \mathrm{d}$ (Scott, 1969); with direct toxic effects only seen after intraruminal infusion of savagely high concentrations of $40 \mathrm{mmol} / \mathrm{kg} \cdot \mathrm{d}$ (Bohman et al., 1969). Considering that the intake of potassium continues to increase worldwide due to modern fertilization techniques, surprisingly little information is available on the mechanism of potassium homeostasis in the ruminant.

\footnotetext{
* Supported by the German Science Foundation (Ma 699/14) and the Margarete Marcus Charity

${ }^{1}$ Corresponding author: e-mail: stumpff@zedat.fu-berlin.de
} 
As in humans, intestinal absorption of potassium in the ruminant species is rapid and almost total (90\%) (Khorasani et al., 1997). Thus, the contribution of the rumen to total digestibility of $\mathrm{K}^{+}$has to be seen as small. Depending on dietary intake, an accumulation of the element in the ruminal cavity can be observed (Sellers and Dobson, 1960), with concentrations reaching $100 \mathrm{mmol} / \mathrm{l}$ so that as much as $31 \%$ of total body potassium can be found in the rumen (Belyea et al., 1978).

Thus, the rumen apparently functions as a redistribution space for potassium in addition to the classical intracellular compartment (Giebisch, 1998), and efflux of $\mathrm{K}^{+}$across the ruminal epithelium must be limited. Indeed, studies of $\mathrm{K}^{+}$secretion under low $\mathrm{K}^{+}$conditions suggest a very low permeability of the apical membrane to $\mathrm{K}^{+}$(Leonhard-Marek and Martens, 1996). However, an elevation of ruminal $\mathrm{K}^{+}$ concentration strongly changes the potential difference over the tissue not only in vitro (Ferreira et al., 1966), but also in vivo (Sellers and Dobson, 1960; Scott, 1966; Martens and Blume, 1986), suggesting the opposite. It should be noted that the in vivo potential cannot represent a Nernst-equilibrium but has to be maintained by a steady flow of ions.

In order to resolve these seemingly contradictory observations, detailed knowledge is needed about the underlying conductances at the level of the cell. We demonstrate that the conductance of ruminal $\mathrm{K}^{+}$channels increases with the potassium concentration, so that high $\mathrm{K}^{+}$should depolarize the apical membrane as suggested (Leonhard-Marek and Martens, 1996). In addition, we demonstrate that cytosolic magnesium regulates sodium influx into ruminal cells not only in the absence of extracellular calcium as demonstrated previously (Leonhard-Marek et al., 2005), but also under physiological conditions. Based on these findings and a literature study, it is possible to establish a model for the regulation of potassium efflux from the rumen that may explain the ability of this organ to function as a redistribution space for potassium homeostasis.

\section{MATERIAL AND METHODS}

Cells from the rumen of freshly slaughtered sheep were harvested, cultured and measured essentially as reported previously (Abdoun et al., 2005; Leonhard-Marek et al., 2005). Patch-clamp measurements were performed using an EPC 9 patchclamp amplifier (HEKA elektronic, Lambrecht, Germany) and TIDA for Windows Software (HEKA elektronic, Lambrecht, Germany). Current responses were recorded continuously at $100 \mathrm{~Hz}$ using a protocol that generated steps of $200 \mathrm{~ms}$ duration to voltages between $-120 \mathrm{mV}$ and $100 \mathrm{mV}$ in $20 \mathrm{mV}$ steps, returning to a holding potential of $-40 \mathrm{mV}$ for $200 \mathrm{~ms}$ in between. In addition, conventional voltage pulse protocols were used that recorded data at a much higher sampling 
rate of $5 \mathrm{kHz}$ and a stepsize of $10 \mathrm{mV}$ within the same voltage range. Pipette solution contained $\left(\mathrm{mmol} \cdot l^{-1}\right): 1 \mathrm{KH}_{2} \mathrm{PO}_{4}, 10 \mathrm{Hepes}, 0.8 \mathrm{CaCl}_{2}, 5 \mathrm{EGTA}, 123 \mathrm{~K}$ gluconate and $10 \mathrm{NaCl}$, with or without $0.9 \mathrm{MgSO}_{4}$, as indicated. Extracellular solutions contained: $1 \mathrm{NaH}_{2} \mathrm{PO}_{4}, 5 \mathrm{KCl}, 10 \mathrm{Hepes}, 1.7 \mathrm{CaCl}_{2}, 0.9 \mathrm{MgCl}_{2}$ to which either $130 \mathrm{NaCl}, 130 \mathrm{KCl}$ or 130 choline chloride were added. All voltages were corrected for liquid junction potential.

\section{RESULTS}

As in a previous study (Stumpff et al., 2004; Leonhard-Marek et al., 2005), $\mathrm{Na}$ current could be stimulated by removing $\mathrm{Ca}^{2+}$ and $\mathrm{Mg}^{2+}$ from the bath, with current into the cell rising to $328 \pm 82 \%(\mathrm{n}=31 ; \mathrm{P}=0.009)$. Outward current rose less dramatically to $150 \pm 19 \%,(\mathrm{n}=31 ; \mathrm{P}=0.01)$. Cells depolarized from $-27 \pm 2 \mathrm{mV}$ to $-21 \pm 3 \mathrm{mV}(\mathrm{P}=0.0004)$. However, when external $\mathrm{Na}^{+}$was replaced by choline in a solution containing physiological concentrations of $\mathrm{Ca}^{2+}$ and $\mathrm{Mg}^{2+}$, no significant effects could be observed, although a small reductions of inward and outward current could be detected (to $93 \pm 5 \% ; \mathrm{P}=0.09$ and $92 \pm 4 \% ; \mathrm{P}=0.07 ; \mathrm{n}=16$ ). Reversal potential shifted slightly $(\mathrm{P}=0.08)$ towards more negative values. Effects of removing $\mathrm{Na}^{+}$became significant after cytosolic $\mathrm{Mg}^{2+}$ was reduced by removing the ion from the pipette solution, with inward current dropping to $67 \pm 5 \%(\mathrm{n}=10$; $\mathrm{P}=0.006)$. Outward current remained unchanged $(\mathrm{P}=0.6)$. Reversal potential dropped to $-43 \pm 4 \mathrm{mV}(\mathrm{P}=0.0002)$.
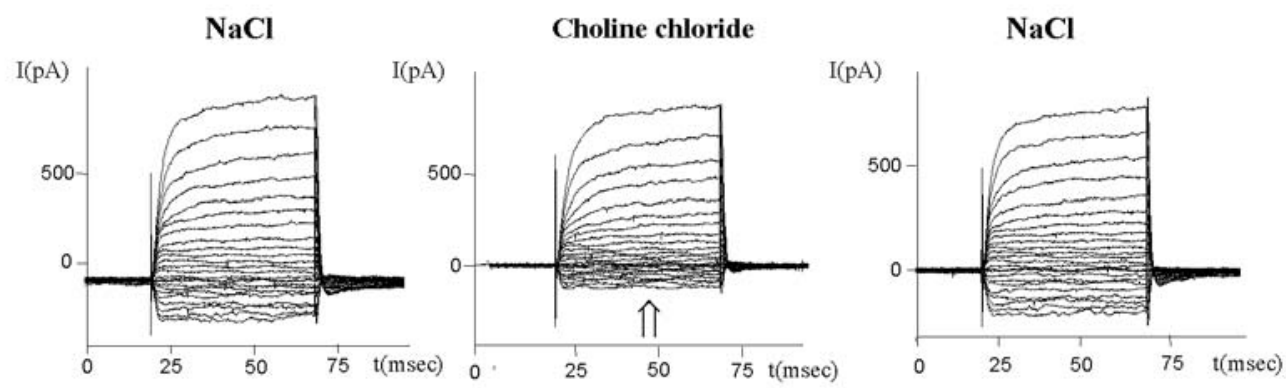

Figure 1. Whole cell currents of cell filled with a $\mathrm{Mg}+$ - free pipette solution. Inward current ( $)$ was higher in $\mathrm{NaCl}$ bath solution than in choline chloride solution

When external solution was changed from $\mathrm{NaCl}$ to $\mathrm{KCl}$ Ringer, inward current at $-120 \mathrm{mV}$ increased from 100 to $344 \pm 52 \%(\mathrm{n}=20 ; \mathrm{P}=0.0002)$. In most cells, outward current could also be seen to increase to a mean value of $122 \pm 10 \%$ $(\mathrm{P}=0.004)$.

Reversal potential shifted from $-29 \pm 3 \mathrm{mV}$ to $-9 \pm 3 \mathrm{mV}$. To exclude an activation of chloride conductances by potassium, external chloride was removed from the 
solutions. In the presence of $\mathrm{Na}$, outward current decreased to $70 \pm 8 \%(\mathrm{P}=0.02)$, and cells depolarized to $-15 \pm 3 \mathrm{mV}(\mathrm{n}=13 ; \mathrm{P}=0.0002)$. Inward current did not change significantly $(\mathrm{P}=0.4)$. Replacement of Na-gluconate by K-gluconate led to complete depolarization $(-1 \pm 2, \mathrm{n}=18 ; \mathrm{P}=0.0001)$ with induction of inward current as before. Mean outward current in K-gluconate solution rose to $142 \pm 22 \%(\mathrm{P}=0.07)$, suggesting that efflux of potassium was enhanced in the high potassium solution.

\section{DISCUSSION}

The results of this study show that the non-selective cation channel of the rumen is regulated by changes in cytosolic $\mathrm{Mg}^{2+}$ concentration not only in the absence of external $\mathrm{Ca}^{2+}$ (Stumpff et al., 2004; Leonhard-Marek et al., 2005) but also in physiological solutions. We were also able to show that the $\mathrm{K}^{+}$conductance of ruminal epithelial cells rises with an increase in $\mathrm{K}^{+}$, as observed in the kidney (Sackin et al., 2001). In light of basolateral and apical expression of $\mathrm{K}^{+}$channels by the rumen in addition to the paracellular pathway (Leonhard-Marek and Martens, 1996), the question arises how the ruminal epithelium is able to maintain high gradients for $\mathrm{K}^{+}$ from lumen to blood (Sellers and Dobson, 1960).

It is possible to estimate the amount of $\mathrm{K}^{+}$that would flow through the ruminal epithelium in the absence of any regulatory mechanisms. Under in vivo conditions, the potential across the ruminal epithelium changes from $30 \mathrm{mV}$ to $60 \mathrm{mV}$ (blood side positive) when ruminal $\mathrm{K}^{+}$is increased by $80 \mathrm{mmol} / 1$ (Scott, 1966). Assuming a conductance $\mathrm{G}_{\mathrm{t}}$ of about $2.5 \mathrm{mS} / \mathrm{cm}^{2}$ (Leonhard-Marek and Martens, 1996), and a ruminal absorptive surface area of $4 \mathrm{~m}^{2}$ (Dobson, 1959), electrogenic flux should equal $\mathrm{I}=\mathrm{G}_{\mathrm{t}} \cdot \mathrm{U}$ or some $2.7 \mathrm{moles} /$ day for sheep of $50 \mathrm{~kg}$, or $54 \mathrm{mmol} / \mathrm{kg} \cdot \mathrm{d}$. Since this (toxic) amount exceeds dietary intake of $\mathrm{K}^{+}$in this study and others (Sellers and Dobson, 1960; Martens and Blume, 1986), we suggest that the potential represents an increase in the active transport of $\mathrm{Na}^{+}$.

But how is the conductance of the apical membrane for $\mathrm{Na}^{+}$adjusted? We suggest that the well-known detrimental effects of $\mathrm{K}^{+}$on ruminal $\mathrm{Mg}^{2+}$ uptake may provide a clue (Martens and Schweigel, 2000). Reduction of cytosolic $\mathrm{Mg}^{2+}$ concentration should open the non-selective cation channel, stimulate apical influx of $\mathrm{Na}^{+}$and basolateral efflux via the $\mathrm{Na}^{+} / \mathrm{K}^{+}$-ATPase. The corresponding rise in transepithelial potential should reduce the electrochemical gradient for the efflux of $\mathrm{K}^{+}$. Elevation of ruminal $\mathrm{K}^{+}$concentration should follow and is observed, as is the corresponding absorption of appropriate amounts of $\mathrm{Na}^{+}$from the rumen to maintain ruminal osmolarity (Sellers and Dobson, 1960; Scott, 1966; Warner and Stacy, 1972). While most of this $\mathrm{Na}^{+}$is eventually recirculated with saliva (Silanikove and Tadmor, 1989), an increase in the urinary excretion of $\mathrm{Na}^{+}$can be observed almost immediately after ingestion of a high $\mathrm{K}^{+}$meal (1-3 h) (Rabinowitz 
et al., 1984), long before the bulk of ruminal fluid reaches the small intestine. Onset of $\mathrm{K}^{+}$excretion in sheep switched to a high $\mathrm{K}^{+}$diet is equally rapid and not related to a rise in plasma $\mathrm{K}^{+}$(Rabinowitz et al., 1984), possibly reflecting the kaliuresis associated with an increase in the delivery of $\mathrm{Na}^{+}$to the distal nephron (Giebisch, 1998).

It appears that the negative effects of a reduction in the uptake of magnesium by high dietary intake of $\mathrm{K}^{+}$(Martens and Schweigel, 2000) are balanced by the positive effects of a redistribution of $\mathrm{K}^{+}$into the ruminal cavity. However, the mechanisms that allow ruminants to compensate for high intakes of $\mathrm{K}^{+}$may be exhausted by the increasing accumulation of $\mathrm{K}^{+}$in soils and forage. In addition, the organic anions that are taken up bound to $\mathrm{K}^{+}$and not balanced by organic cations may lead to problems in acid base balance such as those seen in parturient paresis (Goff, 2004). Finally, it should be noted that maintenance of a high rumenblood $\mathrm{K}^{+}$gradient requires energy. Seen from this perspective, reducing the use of high potassium fertilizers in farming may become an increasingly attractive economic alternative.

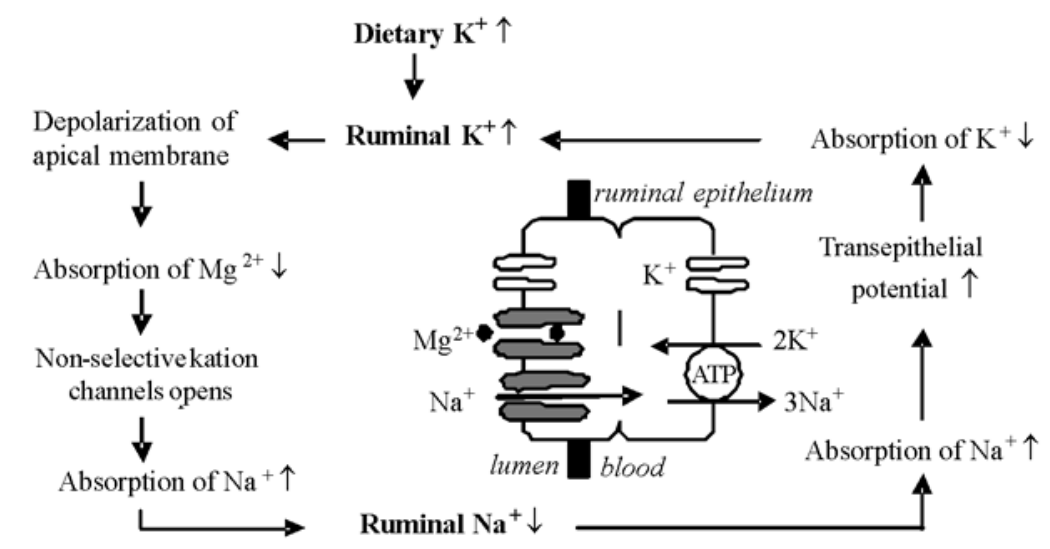

Figure 2. Model of ruminal transport. Efflux of $\mathrm{K}^{+}$through the ruminal epithelium is controlled by the transepithelial potential (blood side positive). $\mathrm{K}^{+}$is concentrated in the rumen which thus functions as an additional space for the redistribution of potassium

\section{ACKNOWLEDGMENTS}

We would like to thank Gabriele Kiselowski and Bernd Anders for technical help. 


\section{REFERENCES}

Abdoun K., Stumpff F., Wolf K., Martens H., 2005. Modulation of electroneutral Na transport in sheep rumen epithelium by luminal ammonia. Amer. J. Physiol. 289, G508-G520

Belyea R.L., Martz F.A., Young R.D., Clark J.L., 1978. Effects of dietary potassium and rumen contents upon k estimation of body composition in dairy cattle. J. Anim. Sci. 46, 320-327

Bohman V.R., Lesperance A.L., Harding G.D., Grunes D.L., 1969. Induction of experimental tetany in cattle. J. Anim. Sci. 29, 99-102

Dobson A., 1959. Active transport through the epithelium of the reticulo-rumen sac. J. Physiol. 146, 235-251

Ferreira H.G., Harrison F.A., Keynes R.D., 1966. The potential and short-circuit current across isolated rumen epithelium of the sheep. J. Physiol. 187, 631-644

Giebisch G., 1998. Renal potassium transport: Mechanisms and regulation. Amer. J. Physiol. 274, F817-F833

Goff J.P., 2004. Macromineral disorders of the transition cow. Vet. Clin. N. Amer. Food Anim. Pr. 20, 471-494

Khorasani G.R., Janzen R.A., McGill W.B., Kennelly J.J., 1997. Site and extent of mineral absorption in lactating cows fed whole-crop cereal grain silage of alfalfa silage. J. Anim. Sci. 75, 239-248

Leonhard-Marek S., Martens H., 1996. Effects of potassium on magnesium transport across rumen epithelium. Amer. J. Physiol. 271, G1034-G1038

Leonhard-Marek S., Stumpff F., Brinkmann I., Breves G., Martens H., 2005. Basolateral Mg2+/Na+ exchange regulates apical nonselective cation channel in sheep rumen epithelium via cytosolic Mg2+. Amer. J. Physiol. Gastrointest. L. 288, G630-G645

Martens H., Blume I., 1986. Effect of intraruminal sodium and potassium concentrations and of the transmural potential difference on magnesium absorption from the temporarily isolated rumen of sheep. Quart. J. Exp. Physiol. 71, 409-415

Martens H., Schweigel M., 2000. Pathophysiology of grass tetany and other hypomagnesemias. Implications for clinical management. Vet. Clin. N. Amer. Food Anim. Pr. 16, 339-368

Rabinowitz L., Sarason R.L., Yamauchi H., 1984. Sheep renal potassium excretion: Efferent kaliuretic regulatory factors. Amer. J. Physiol. 247, F520-F526

Sackin H., Syn S., Palmer L.G., Choe H., Walters D.E., 2001. Regulation of ROMK by extracellular cations. Biophys. J. 80, 683-697

Scott D., 1966. The effects of sodium depletion and potassium supplements upon electrical potentials in the rumen of the sheep. Quart. J. Exp. Physiol. Cogn. Med. Sci. 51, 60-69

Scott D., 1969. The effects of variations in water or potassium intake on the renal excretion of potassium in sheep. Quart. J. Exp. Physiol. Cogn. Med. Sci. 54, 16-24

Sellers A.F., Dobson A., 1960. Studies on reticulo-rumen sodium and potassium concentration and electrical potentials in sheep. Res. Vet. Sci. 1, 95-102

Silanikove N., Tadmor A., 1989. Rumen volume, saliva flow rate, and systemic fluid homeostasis in dehydrated cattle. Amer. J. Physiol. 256, R809-R815

Stumpff F., Brinkmann I., Schweigel M., Martens H., 2004. High potassium diet, sodium and magnesium in ruminants: The story is not over. N.P. Joshi, T.H. Heredt (Editors). Production Diseases in Farm Animals. Wageningen Academic Publishers, pp. 284-285

Warner A.C., Stacy B.D., 1972. Water, sodium and potassium movements across the rumen wall of sheep. Quart. J. Exp. Physiol. Cogn. Med. Sci. 57, 103-119 